\title{
Bladder cancer among hairdressers: a meta-analysis
}

\author{
Melanie Harling, ${ }^{1}$ Anja Schablon, ${ }^{1}$ Grita Schedlbauer, ${ }^{1}$ Madeleine Dulon, ${ }^{1}$ \\ Albert Nienhaus ${ }^{2}$
}

${ }^{1}$ Institution for Statutory Accident Insurance and Prevention in the Health and Welfare Services, Department of Occupational Health Research, Hamburg, Germany

${ }^{2}$ University Medical Center Hamburg-Eppendorf, Institute for Health Service Research in Dermatology and for Health Care Workers, Hamburg, Germany

\section{Correspondence to}

Melanie Harling, Institution for Statutory Accident Insurance and Prevention in the Health and Welfare Services, Department of Occupational Health Research, Pappelallee 35/37, Hamburg 22089, Germany:

melanie.harling@bgw-online.de

Accepted 2 December 2009

This paper is freely available online under the BMJ Journals

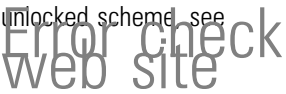

\begin{abstract}
Background Occupational risks for bladder cancer in hairdressers by using hair products have been examined in many epidemiological studies. But owing to small sample sizes of the studies and the resulting lack of statistical power, the results of these studies have been inconsistent and significant associations have rarely been found.

Methods We conducted a meta-analysis to determine summary risk ratios (SRRs) for the risk of bladder cancer among hairdressers. Studies were identified by a MEDLINE, EMBASE, CENTRAL search and by the reference lists of articles/relevant reviews. Statistical tests for publication bias and for heterogeneity as well as sensitivity analysis were applied. In addition, the study quality and the risk of bias were assessed using six criteria.
\end{abstract}

Results 42 studies were included and statistically significantly increased risks around 1.3-1.7 were found for all but one analysis. The SRR increased with duration of employment from 1.30 (95\% Cl 1.15 to 1.48) for 'ever registered as hairdresser' to $1.70(95 \% \mathrm{Cl} 1.01$ to 2.88$)$ for 'job held $\geq 10$ years'. No difference was found between the risk for smoking-adjusted data (SRR 1.35, 95\% Cl 1.13 to 1.61 ) and no adjustment (SRR 1.33, 95\% $\mathrm{Cl} 1.18$ to 1.50$)$. Studies assessed as being of high quality $(n=11)$ and of moderate quality $(n=31)$ showed similar SRRs. There was no evidence of publication bias or heterogeneity in all analyses.

Conclusion In summary, our results showed an increased and statistically significant risk for bladder cancer among hairdressers, in particular for hairdressers in jobs held $\geq 10$ years. Residual confounding by smoking cannot be totally ruled out. Because of the long latency times of bladder cancer it remains an open question whether hairdressers working prior to 1980 and after 1980, when some aromatic amines were banned as hair dye ingredients, have the same risk for bladder cancer.

\section{INTRODUCTION}

Until the end of the 1970s several aromatic amines (eg, 4-aminobiphenyl, benzidine, 2-naphthylamin, 4-chloro-o-toluidine) were used in hair dyes and other hair products, which were identified as carcinogenic for urothelial cancers. ${ }^{12}$ In response, regulatory action was taken in 1978 and some aromatic amines were banned as hair dye ingredients in the European Union, but other aromatic amines have still been used in hair dyes. Therefore today, there seems to be no relevant bladder cancer risk from the use of hair dyes. But human urothelial cancers, chemically induced by aromatic amines, typically have latency times often longer than 30 or 40 years. ${ }^{2-5}$ As earlier exposures to aromatic amines used in hair dyes could have an impact decades later,

\section{What this paper adds}

- Aromatic amines which were identified as carcinogenic for urothelial cancers were used in hair dyes and other hair products until the end of the 1970s.

- In response, many epidemiological studies have been conducted to examine occupational risk factors for bladder cancer among hairdressers, but the results of these studies have been inconsistent.

- The results of the present meta-analysis on 42 studies suggest that there is robust evidence for an increased risk of bladder cancer among hairdressers, in particular for hairdressers in a job held $\geq 10$ years.

- The data available from the individual studies do not provide adequate information to draw a conclusion regarding the question whether current occupational exposure to modern hair products is still related to some excess bladder cancer risk among hairdressers and therefore further research is needed.

this means that the possibility of bladder cancer in hairdressers having worked with hair dyes during earlier decades (prior 1980) should be taken into account. Furthermore, a study conducted by Turesky et al ${ }^{6}$ demonstrates that aromatic amines with carcinogenic effect (derivatives of 4-aminobiphenyl) are still present in some commercial hair dyes.

The risk for bladder cancer among hairdressers has been examined in many epidemiological studies. But owing to small sample sizes and the resulting lack of statistical power the results of these studies have been inconsistent and significant associations have rarely been found.

Two reviews summarised available evidence on the association between hair dyes and cancer. ${ }^{27}$ But neither were the search strategies or inclusion criteria for the studies explained, nor were extensive meta-analyses carried out. Recently Reulen et al conducted a meta-analysis on the association between bladder cancer and occupation, among others in hairdressers. A small but significantly increased risk was determined for hairdressers in the pooled analysis, even for smoking-adjusted data. But due to the fact that Reulen et $a l^{8}$ worked on a total of over 60 occupational groups, a more detailed analysis for hairdressers was not possible and is still missing. None of the three reviews covered duration of exposure.

Therefore we conducted a meta-analysis to determine the risk for bladder cancer among 
hairdressers in more detail: pooled risk estimators stratified by study design, gender, study quality, duration of employment as hairdresser and adjusted by smoking were calculated.

\section{MATERIALS AND METHODS \\ Search strategy and screening form}

We conducted a MEDLINE, EMBASE, CENTRAL search for articles published after 1970 in October 2008 (update February 2009). The search terms included 'Urinary Bladder Neoplasms' [MeSH], 'occupation', 'occupational exposure' or 'hairdresser' and 'hair dye' or 'hair color/colour' or 'hair colourant/colorant'. Additional studies were identified from the reference list of articles and relevant reviews. Three authors screened all abstracts and full texts by an initially developed screening form, which included the following inclusion criteria:

- Study design: randomised controlled trial (RCT), casecontrol study or cohort study

- Study population: the population included hairdressers

- Exposure: job held as a hairdresser is clearly stated

- Analysis: occupation is determined as a risk factor

- Outcome: clinically confirmed diagnosis of bladder cancer

- Languages: English and German

Studies which do not meet the inclusion criteria were excluded and the reasons for exclusion were noted. When the information provided by abstracts was insufficient to decide on inclusion or exclusion, we retrieved and evaluated the full text.

\section{Assessment of study quality and the risk of bias}

In concordance with the literature for the assessment of study quality of observational studies ${ }^{9-13}$ we generated six criteria. Each of these criteria were scored with one, two or three stars as follows:

1. A clearly stated $\operatorname{aim}^{9}{ }^{10}$ : reported and adequate $\left({ }^{* * *}\right)$, reported, but inadequate $\left({ }^{* *}\right)$, not reported $\left({ }^{*}\right)$.

2. Response rate/trace rate ${ }^{11} 12$ : $\geq 70 \%\left({ }^{* * *}\right), \geq 50 \%\left({ }^{* *}\right),<50 \%$ $(*)$.

3. Comparability of subjects ${ }^{10-12}$ : population-based controls $\left({ }^{* *}\right)$, matching $\left(^{* *}\right)$, no matching $\left(^{*}\right)$.

4. Elevation of exposure ${ }^{12}$ : definition for job held $\geq 5$ years $\left(*^{* *}\right)$, definition for job held $<5$ years $\left(^{* *}\right)$, definition for 'ever registered as a hairdresser' or not reported $\left(^{*}\right)$.

5. Adequate statistical analysis and confounding ${ }^{10} 111^{13}$ : adjustment for smoking $\left({ }^{* * *}\right)$, partially adjusted $\left({ }^{* *}\right)$, non-adequate statistics or not adjusted $\left(^{*}\right)$.

6. Discussion of limitations and generalisability ${ }^{9}$ : limitations and generalisability discussed $\left({ }^{* *}\right)$, partially discussed $\left({ }^{* *}\right)$, not discussed $(*)$.

Two authors individually graded the study quality by a predefined form. In a consensus meeting the results were compared and potential disagreement was resolved following discussion.

We developed the grading system according to the process of the Methodological Index for Non-Randomised Studies (MINORS). ${ }^{10}$ Overall, 18 stars could be achieved. By summing up the stars, the studies were classified according to their quality: 17-18 stars=high-quality level

$\leq 16$ stars $=$ moderate-quality level

\section{Evaluation of heterogeneity}

Heterogeneity is a consequence of methodological diversity between the studies and manifests itself in the observed effects being more different from each other than one would expect by random error (chance) alone. The absence of heterogeneity among studies indicates between-study comparability. We used the $\chi^{2}$ test to test for heterogeneity. Because the $\chi^{2}$ has lower power in the situation of a meta-analysis when studies have small sample size, we used a $p$ value of 0.10 to determine statistical significance for heterogeneity. This means a nonsignificant result indicates absence of heterogeneity. ${ }^{11}$

\section{Statistical pooling}

The data for the statistical analysis were extracted by a predefined data extraction form. For the overall meta-analysis we extracted the sample size, the sizes of the case group and control group, the effect estimate, given as the OR or the standardised incidence ratio, or standardised mortality ratio (both abbreviated as SMR), respectively, with a 95\% CI. When necessary, we contacted the authors of some studies for further clarification. Data extraction was individually carried out by two reviewers.

A summary risk ratio (SRR) was calculated using the generic inverse variance approach. The weight given to each study in the inverse variance approach is chosen to be the inverse of the variance of the effect estimate (ie, one over the square of its standard error $\left(1 / S E_{i}^{2}\right)$ ) which calculates a weighted SRR as shown in the following formula ${ }^{11}$ :

$$
S R R=\frac{\sum\left(T_{i} / S E_{i}^{2}\right)}{\sum\left(1 / S E_{i}^{2}\right)}
$$

$\mathrm{SRR}=$ summary risk ratio, $\mathrm{T}_{\mathrm{i}}=$ risk estimate in study $\mathrm{i}, \mathrm{SE}_{\mathrm{i}}=$ standard error of the risk estimate in study $\mathrm{i}$.

If $S E$ was not given by the individual study, an approximate standard error of the logarithm of the risk estimate was calculated as follows ${ }^{11}$ :

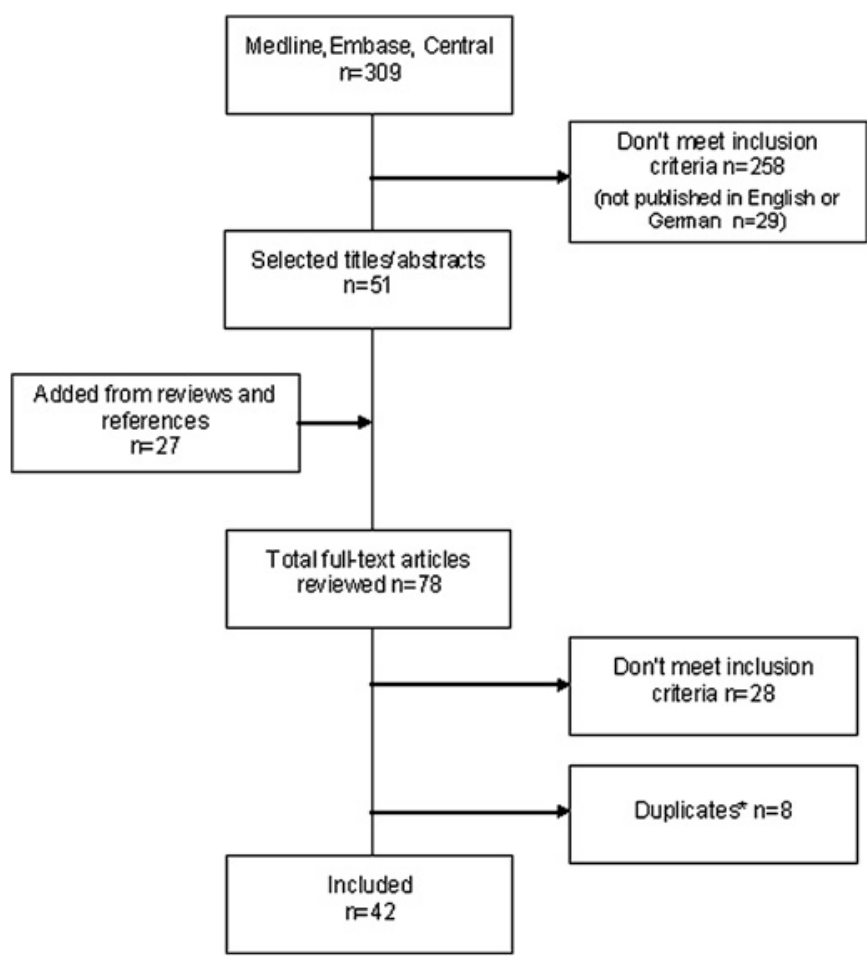

Figure 1 Flow diagram of the process of identifying and including studies. *When the study population was described in more than one study, only the study with the greatest number of cases was included. All others were excluded as duplicates. 
Table 1 Abstracted study information and risk estimates for bladder cancer from the individual studies and assessment of study quality

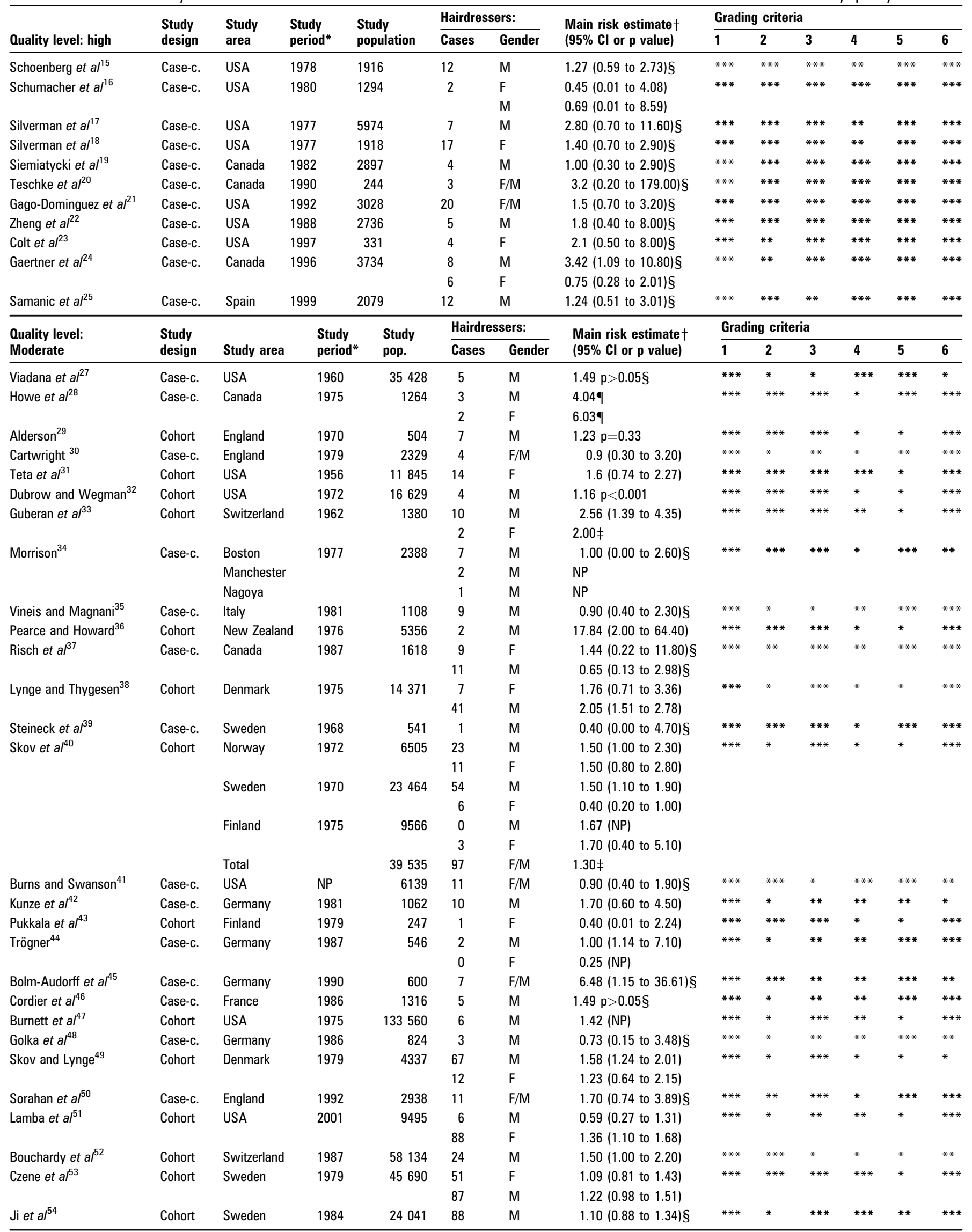


Table 1 Continued

\begin{tabular}{|c|c|c|c|c|c|c|c|c|c|c|c|c|c|}
\hline \multirow{2}{*}{$\begin{array}{l}\text { Quality level: } \\
\text { Moderate }\end{array}$} & \multirow{2}{*}{$\begin{array}{l}\text { Study } \\
\text { design }\end{array}$} & \multirow[b]{2}{*}{ Study area } & \multirow{2}{*}{$\begin{array}{l}\text { Study } \\
\text { period* }\end{array}$} & \multirow{2}{*}{$\begin{array}{l}\text { Study } \\
\text { pop. }\end{array}$} & \multicolumn{2}{|c|}{ Hairdressers: } & \multirow{2}{*}{$\begin{array}{l}\text { Main risk estimate } \dagger \\
(95 \% \mathrm{Cl} \text { or } \mathrm{p} \text { value) }\end{array}$} & \multicolumn{6}{|c|}{ Grading criteria } \\
\hline & & & & & Cases & $\overline{\text { Gender }}$ & & $\overline{1}$ & 2 & 3 & 4 & 5 & 6 \\
\hline \multirow[t]{3}{*}{ Dryson et $a l^{55}$} & Case-c. & New Zealand & 2003 & 684 & 6 & $\mathrm{~F} / \mathrm{M}$ & $9.15(1.60$ to 52.22$) \S$ & $* * *$ & $*$ & $* * *$ & $* *$ & $* * *$ & $* * *$ \\
\hline & & & & & 2 & $M$ & $5.41 \neq$ & & & & & & \\
\hline & & & & & 4 & $\mathrm{~F}$ & 9.95 (1.37 to 72.21$)$ & & & & & & \\
\hline Golka et $a l^{56}$ & Case-c. & Germany & 1993 & 492 & 4 & $M$ & $4.9(0.85$ to 28.39$) \S$ & $* * *$ & ** & $* *$ & $* *$ & $* * *$ & $* * *$ \\
\hline
\end{tabular}

Case-c, case-control design; cohort, retrospective cohort design including registry data; M, male; F, female; Grading criteria, 1 (clearly stated aim), 2 (response rate / trace rate), 3 (comparability of subjects), 4 (elevation of exposure), 5 (adequate statistical analysis and confounding), 6 (discussion of limitations and generalisability), NP, not presented; bold, statistically significant.

${ }^{*}$ Mean year of ascertainment of bladder cancer cases.

†Effect estimates used for the overall meta-analysis, stratified data not presented in table.

$\neq$ Calculated by data given by the original study.

$\S$ Smoking-adjusted (unadjusted data not given)

IIf extended data are provided but the count in the exposed control group was 0 , the risk estimator and SE were calculated by adding a correction of 0.5 events in order to include the study in the meta-analysis as suggested by the Cochrane Collaboration. ${ }^{11}$

$$
S E=\sqrt{(1 / A+1 / C)}
$$

$\mathrm{A}=$ events occurred in the case group, $\mathrm{C}=$ events occurred in the control group.

In case of homogeneity we used a variation of the inverse variance approach with a fixed effect model and in case of heterogeneity we used the random effect model. ${ }^{11} 14$

For the overall meta-analysis we used unadjusted data. If unadjusted data were not published by the individual studies, smoking-adjusted effect estimates were used for the overall meta-analysis. For studies where only stratified data on sex were given, we summarised the data and calculated the effect estimate among both sexes combined to calculate the overall SRR. All analyses were carried out using Review Manager 5 and Microsoft Excel 2007

\section{Stratification}

For the stratified analysis we additionally extracted, where given, smoking-adjusted and stratified data for various factors. We calculated the SRR stratified for study design, gender, study period (defined as the mean year of ascertainment of the bladder cancer cases), study area, adjustment for smoking and study quality. If no adjustment or stratification were given, the studies were excluded from the stratified analysis. In addition, we analysed whether the SRR varies by duration of job held as a hairdresser, because demonstration of this association would lend additional weight to a suspected cause-effect relationship. Therefore three mutually non-exclusive categories were defined: ever registered as hairdresser, job held $\geq 5$ years and job held $\geq 10$ years. If no definition for job held was given or if the categorisation used in the study did not fit neatly in this categories, the studies were excluded from this analysis.

\section{Sensitivity analysis}

Sensitivity analysis was carried out by recalculation of SRR after exclusion of each individual study in turn. This method of sensitivity analysis indicates the importance of each individual study in the combined meta-analysis and allows determination of whether any of these had a disproportionate influence. ${ }^{11}$

\section{Publication bias}

Following Egger et al ${ }^{57}$ we explored publication bias due to study size. First, we plotted the effect estimator versus the precision of the estimate (defined as the inverse of the standard error $\left(1 / S E_{\mathrm{i}}\right)$ ) to explore publication bias due to study size. An asymmetry of this funnel plot indicates publication bias. ${ }^{57}$ Second, we tested the funnel plot asymmetry by a linear regression approach on the natural logarithm scale of the effect estimator. In this method the standard normal deviate (SND), defined as the effect estimate divided by its standard error, is regressed against the precision. The intercept provides a measure of asymmetry-the larger its deviation from zero, the more pronounced the asymmetry. ${ }^{57}$

Table 2 Pooled estimates of bladder cancer among hairdressers: stratified analysis

\begin{tabular}{|c|c|c|c|c|c|}
\hline \multirow[b]{2}{*}{ Stratified analysis Set of studies } & \multirow[b]{2}{*}{$\begin{array}{l}\text { No of } \\
\text { studies }\end{array}$} & \multicolumn{2}{|c|}{ Pooled estimators } & \multicolumn{2}{|c|}{ Homogeneity } \\
\hline & & SRR & $95 \% \mathrm{Cl}$ & $\chi^{2}$ & $\begin{array}{l}\mathbf{p} \\
\text { Value }\end{array}$ \\
\hline All studies & 42 & 1.34 & 1.21 to 1.48 & 39.88 & 0.52 \\
\hline \multicolumn{6}{|l|}{ Gender } \\
\hline Data for female hairdressers ${ }^{16} 18232426283133373840434449515355$ & 17 & 1.25 & 1.05 to 1.50 & 15.55 & 0.48 \\
\hline Data for male hairdressers ${ }^{15-17} 192224-2932-40424446-4951-56$ & 32 & 1.52 & 1.34 to 1.72 & 36.14 & 0.24 \\
\hline \multicolumn{6}{|l|}{ Study period* } \\
\hline Ascertainment of cases $<1979^{15} 171827-343638-4043474953$ & 19 & 1.37 & 1.19 to 1.58 & 12.35 & 0.83 \\
\hline Ascertainment of cases $1980-1989^{16} 19223537424446485254$ & 11 & 1.24 & 1.00 to 1.53 & 7.15 & 0.71 \\
\hline Ascertainment of cases $>1990^{20} 2123-254550515556$ & 10 & 1.42 & 1.16 to 1.75 & 13.82 & 0.13 \\
\hline \multicolumn{6}{|l|}{ Study area $†$} \\
\hline USA/Canada ${ }^{15-24} 26-2831323437414751$ & 20 & 1.28 & 1.08 to 1.52 & 10.69 & 0.93 \\
\hline Europe/Nordic countries ${ }^{25} 293033-3538-4042-46 \quad 48-5052-5456$ & 20 & 1.34 & 1.19 to 1.52 & 21.20 & 0.33 \\
\hline \multicolumn{6}{|l|}{ Adjusted data } \\
\hline Adjusted for smoking ${ }^{15} 17-2527343537394145464850 \quad 54-56$ & 23 & 1.35 & 1.13 to 1.61 & 28.81 & 0.19 \\
\hline No adjustment ${ }^{16} 2628-3336384042-44474951-53$ & 19 & 1.33 & 1.18 to 1.50 & 14.05 & 0.78 \\
\hline \multicolumn{6}{|l|}{ Study quality level } \\
\hline High quality ${ }^{15-25}$ & 11 & 1.35 & 1.03 to 1.77 & 4.77 & 0.91 \\
\hline Moderate quality ${ }^{26-56}$ & 31 & 1.34 & 1.20 to 1.49 & 35.11 & 0.24 \\
\hline
\end{tabular}

*Two studies ${ }^{26}{ }^{41}$ were excluded because study period was not presented in the original study.

†Two studies from New Zealand ${ }^{3555}$ were excluded from this analysis. 


\section{RESULTS}

\section{Studies identified and assessment of study quality}

We identified 309 abstracts from the database search and 27 were added from references $(\mathrm{n}=336)$. Two hundred and fifty-eight were excluded, because they did not meet the inclusion criteria. Of these excluded studies, 29 were published in other languages than English or German, but 26 provided an English abstract. These abstracts were screened and 24 of them were excluded because they did not meet the inclusion criteria. The information of two abstracts was insufficient to decide on inclusion or exclusion. This means that we excluded five studies because of language issues alone. Finally, 78 studies needed to be reviewed as full-text articles and 42 articles met the inclusion criteria (figure 1).

Of the included studies, 28 used a case-control design and 14 studies used a retrospective cohort design. RCTs or prospective cohort studies were not identified. The effect estimate for bladder cancer among hairdressers varied between 0.40 and 17.84, and the studies included from one up to 138 cases in hairdressers. Eleven studies were assessed as being high-quality studies; all of these studies had been case-control studies. Thirtyone studies were assessed as being of moderate quality, with 17 of these studies having a case-control design and 14 having a retrospective cohort design (table 1).

\section{Results of the overall meta-analysis}

The meta-analysis of all included studies $(n=42)$ showed a significantly increased SRR of 1.34 (95\% CI 1.21 to 1.48) and the $\chi^{2}$ showed no evidence of heterogeneity $\left(\chi^{2} 39.88, p=0.52\right)$ (table 2). Visual examination of the funnel plot to assess publication bias reveals no systematic relation between study size and magnitude of the estimator (OR/SMR) (funnel plot not shown). The statistical test applied did not show significant funnel plot asymmetry either (intercept $0.37 ; 95 \%$ CI -0.14 to 0.88 ).

\section{Sensitivity analysis}

Sensitivity analysis by exclusion of each study in turn did not modify the results of the meta-analysis and showed robust results. The SRR ranged from 1.33 to 1.37 and all SRRs were statistically significant (figure 2).

\section{Stratified analysis}

Figure 3 illustrates the forest plot of case-control studies and cohort studies. The SRR calculated for case-control studies was 1.41 (95\% CI 1.51 to 1.74) and for cohort studies 1.32 (95\% CI 1.17 to 1.48). Both plots showed a good overlap of the confidence interval and no evidence of heterogeneity (case-control studies: $\chi^{2}$ 29.86, $p=0.32$; cohort studies: $\chi^{2}$ 9.73, $p=0.72$ ). Drawing the funnel plot of case-control studies (intercept $0.66 ; 95 \% \mathrm{CI}-0.46$ to 1.78 ) and cohort studies (intercept $0.37 ; 95 \% \mathrm{CI}-0.52$ to 1.27 ) separately did not reveal asymmetry (funnel plot not shown).

Significantly increased risks and no evidence of heterogeneity were also found for stratified analysis shown in table 2. Small differences were found between studies stratified by gender: the risk for male hairdressers (SRR 1.52, 95\% CI 1.34 to 1.72) was slightly higher than the risk for female hairdressers (SRR 1.25, $95 \%$ CI 1.05 to 1.50). Significant increased risks, but no trend with time, were found for the set of studies stratified by study period. The SRR for studies with ascertainment of cases $\leq 1979$ was 1.37 ( $95 \%$ CI 1.19 to 1.58), the SRR for studies with ascertainment of cases between 1980 and 1989 was 1.24 (95\% CI 1.00 to 1.53) and the SRR for studies with ascertainment of cases $\geq 1990$ was 1.42 (95\% CI 1.16 to 1.75$)$. Nearly no difference in risk was found between studies from the USA/Canada and Europe/Nordic countries as well as between studies with smoking-adjusted data and studies with no adjustment. Also, no difference in the risk

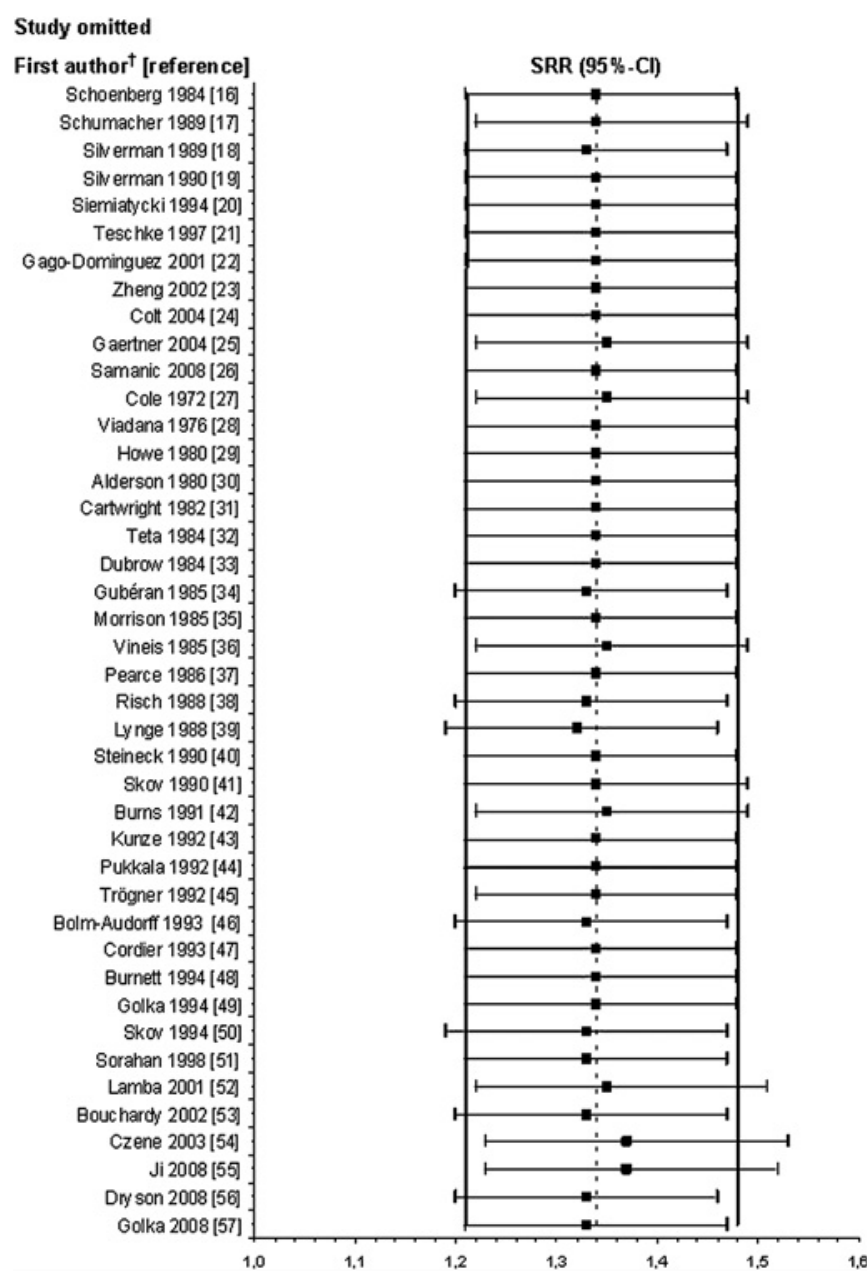

Figure 2 Forest plot showing the influence of excluding each individual study on the summary risk ratio (SRR) obtained using all studies for bladder cancer among hairdressers. Vertical dashed line $=$ SRR obtained using all studies, vertical solid lines $=95 \% \mathrm{Cl}$ of the SRR using all studies, block with line=SRR with $95 \% \mathrm{Cl}$ obtained by omitting the mentioned study. ${ }^{\dagger}$ For convenience reasons only the first author is given.

was shown between studies assessed as being high-quality studies or as being moderate-quality studies (table 2).

\section{Duration of job held}

The risk of bladder cancer increased with the duration of employment as a hairdresser and all analyses showed no evidence of heterogeneity in all three strata. The SRR calculated for studies with data for hairdressers who were ever registered for employment $(\mathrm{n}=19)$ showed a risk of $1.30(95 \%$ CI 1.15 to 1.48). The SRR calculated for studies with stratified data for job as a hairdresser held for $\geq 5$ years $(n=3)$ showed an increased, but not significant risk of 1.52 (95\% CI 0.79 to 2.93 ) and the SRR calculated for studies with stratified data for job held $\geq 10$ years $(n=6)$ showed an increased and significant risk of $1.70(95 \% \mathrm{CI}$ 1.01 to 2.88 ) (figure 4).

\section{DISCUSSION}

We found significantly increased risks for bladder cancer among hairdressers in all but one analyses. To our knowledge this is the first meta-analysis approach covering bladder cancer in hairdressers that tested between-study comparability by evaluation of heterogeneity and that tested for publication bias. Furthermore the duration of employment as a hairdresser was considered for the first time and a predefined quality assessment tool was used. 
Study ${ }^{\dagger}$ [reference]

inverse variance, fixed model

Case-control studies

\begin{tabular}{|c|}
\hline \\
\hline $\begin{array}{l}\text { Schumacher } 1989 \\
\text { Sitverman } 1989\end{array}$ \\
\hline Silverman 1990 \\
\hline Siemiatycki 1994 \\
\hline Teschke 1997 \\
\hline Gago-Dominguez 2001 \\
\hline Zheng 2002 \\
\hline Colt 2004 \\
\hline Gaentner 2004 \\
\hline Samanic 2008 \\
\hline Cole 1972 \\
\hline Viadana 1976 \\
\hline Howe 1980 \\
\hline Cartwright 1982 \\
\hline Morrison 1985 \\
\hline Vineis 1985 \\
\hline Risch 1988 \\
\hline Steineck 1990 \\
\hline Burns 1991 \\
\hline Kunze 1992 \\
\hline Trögner 1992 \\
\hline Bolm-Audorft 1993 \\
\hline Cordier 1993 \\
\hline Golka 1994 \\
\hline Sorahan 1998 \\
\hline Dryson 2008 \\
\hline \\
\hline
\end{tabular}

SRR (95\%-Cl): 1.41 (1.15-1.74)

Heterogeneity: $\mathrm{Chi}^{2}=29.86, \mathrm{p}=0.32$

Retrospective cohort studies including registry data

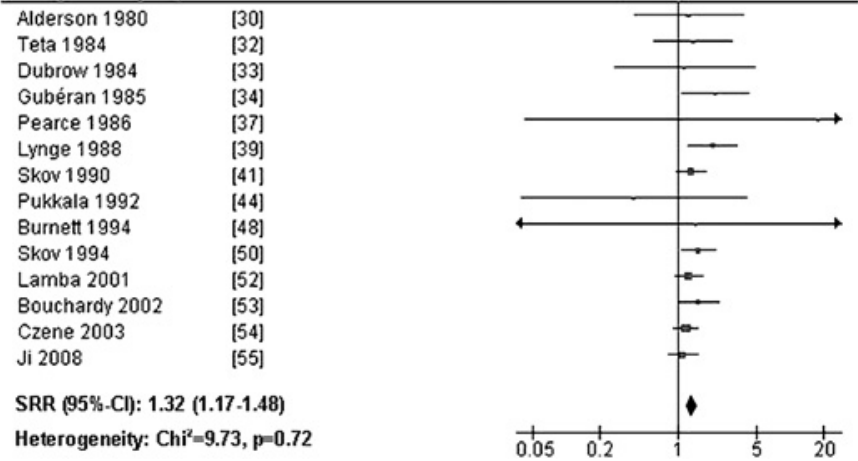

Figure 3 Forest plot of studies by study design. Block=risk estimates (size displays weight), line $=95 \% \mathrm{Cl}$. ${ }^{\dagger}$ For convenience reasons only the first author is given.

\section{Relevant literature and publication bias}

We found 42 studies which met the inclusion criteria. Reulen et $a l^{8}$ found 29 studies which analysed this association. Even though the risk of bladder cancer among hairdressers is methodologically best observed in RCTs or prospective studies, our meta-analysis had to rely on observational studies, because RCTs or prospective studies were not found.

Another point is that the results of a meta-analysis might be affected by publication bias. Publication biases result from the probability that studies with a significant effect are more likely to be published in journals indexed in databases such as MEDLINE than studies which found no effect. In order to avoid such publication bias, we included also studies which were published in German and studies which were not published in indexed journals (eg, results of dissertations ${ }^{44}$ and reports from federal institutes). ${ }^{45}$ In addition, publication biases can also result from language bias, because studies published in other languages than English or German were not included in our meta-analysis. In order to assess potential language bias in our meta-analysis we checked the amount of studies published in other languages found by our search strategy and, if provided, the English abstract for inclusion criteria. Finally, if we had not applied our language restriction, five additional studies would have been included in our meta-analysis. Furthermore we formally tested for publication bias but did not find an indication for asymmetry of the funnel plot and consequently for publication bias.
Results of the meta-analysis and study quality

The SRR for all studies included in our meta-analysis was 1.34. Furthermore, we conducted a sensitivity analysis to evaluate the importance of each study in the overall meta-analysis and we found no evidence for a disproportionate influence of individual studies. In their meta-analysis, Reulen et al ${ }^{8}$ also found a significant but slightly lower risk of 1.24 (no test for heterogeneity or publication bias). In addition, in the review of $\mathrm{La} \mathrm{Vecchia}^{7}$ the observed $(\mathrm{O})$ and expected (E) cases of seven cohort studies were summarised and a risk of 1.4 was calculated by dividing $\mathrm{O} / \mathrm{E}$ (no test of significance).

We pooled the data separately for case-control and cohort studies, because the study design has an impact on the methodological quality of studies. We found nearly the same risk for case-control and cohort studies with a statistically significant SRR of 1.3 and 1.4, respectively, and no evidence of heterogeneity as well as no indication of publication bias. Reulen et al also found nearly no difference between case-control and cohort studies, but with significant SRRs around 1.2, the risk was slightly lower (no test for heterogeneity or publication bias).

In addition, we assessed the quality and the risk of bias of the included studies, because irrespective of the study design there might be other issues of interest in terms of study quality. A number of checklists and indexes have been proposed, but none of these seemed to be suitable for our study question. ${ }^{10} 13$

Study ${ }^{\dagger}$ [reference]

inverse variance, fixed model

Ever registered for employment

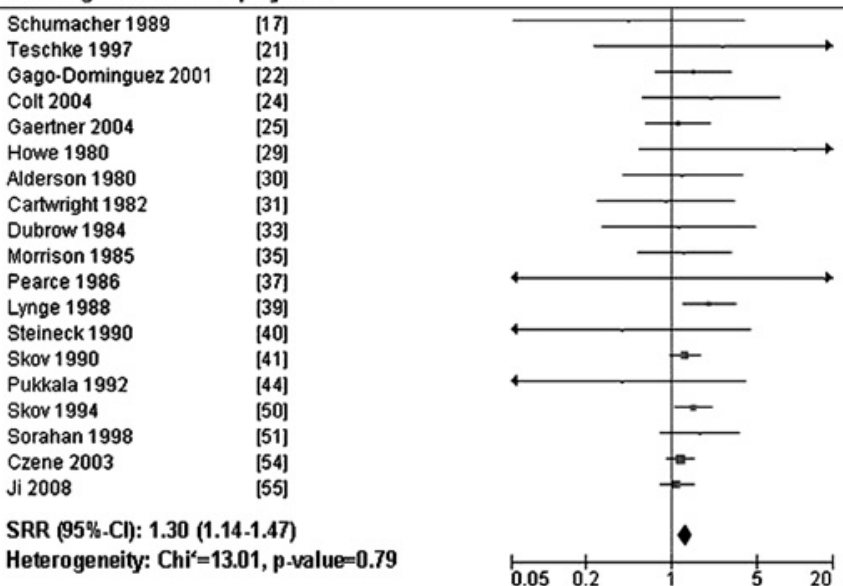

Job held $\geq 5$ years

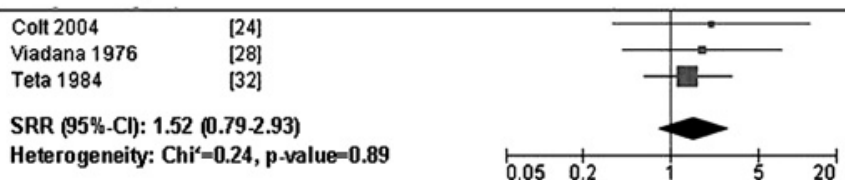

Job held $\geq 10$ years

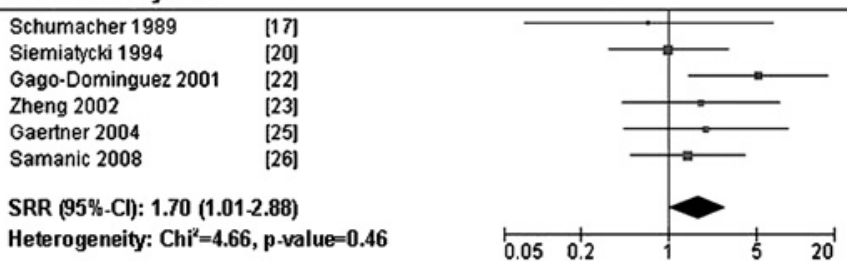

Figure 4 Forest plot of studies by duration of job held as a hairdresser. Block=risk estimates (size displays weight), line $=95 \% \mathrm{Cl} .{ }^{\dagger}$ For convenience reasons only the first author is given. Studies 171826333537 $414244-4851525556$ with no definition or unsuitable definition for job held were excluded form this analysis. 
Therefore in concordance with the literature and on the basis of recommendations for systems to rate the quality of observational studies $^{9-13}$ we developed a quality assessment tool adapted for our study question. This tool has not been validated but it turned out to be suitable for our purposes.

However, following our assessment tool we found only casecontrol studies and no retrospective cohort studies for the highquality level. This is not surprising because registry data have a number of limitations; these were also mostly the reasons for downgrading the study quality. First, information on occupation is not fully registered. ${ }^{47}$ Second, registry data contain no additional information on occupation, for example, about duration of job held. ${ }^{475152}$ And third, information on potential confounders such as smoking is often missing. But well-designed studies based on registry data might also have benefits. They are routinely collected, provide a big amount of data with very little data missing and the data can be determined for several causes of death or diseases. ${ }^{47}$ Therefore registry data can provide important information to some potential health problems, especially for occupational health problems. This is also shown by a comparison study. ${ }^{47}$ The ability of death certificate data was compared with the ability of data of a population-based case-control study to identify high-risk occupations for bladder cancer. In this comparison the rate of agreement was $62 \%$.

Case-control studies might also have limitations and were therefore assessed as being of moderate quality. Reasons were mostly a relatively low response rate and missing stratification for the duration of employment. In addition, the control group of some case-control studies was hospital-based and sometimes the control group was not chosen with matching.

Nevertheless, we found nearly the same risks with a significant SRR around 1.35 for high-quality and moderate-quality studies. In summary, irrespective of the study design and the level of quality we found consistent risks with a significant SRR around 1.3-1.4. This corroborates the interpretation that there is a causal association between bladder cancer and job held as a hairdresser.

\section{Stratified data}

We found significantly elevated risks and no evidence of heterogeneity in all sets of studies. The pooled risk estimator for female and male hairdressers differed slightly with statistically significant SRRs of 1.25 for females and 1.52 for males. More or less the same results were found by Reulen et al. ${ }^{8}$ They also established a slightly higher risk in males than in females. Some authors who found higher risks for male than for female hairdressers conclude that the risk for bladder cancer is mainly caused by exposure with brilliantine, which was used in the past for hair grooming in men. ${ }^{24} 53$ But in contrast, other studies found a higher risk for female than for male hairdressers. ${ }^{265155}$ Nearly no difference in risk was found between studies from the USA/ Canada and studies from Europe/Nordic countries. To our knowledge this comparison was not performed in other metaanalyses on bladder cancer among hairdressers.

Tobacco consumption is a well-established risk factor for bladder cancer. ${ }^{2628303453}$ The pooled risk estimator for smokingadjusted data in our meta-analysis showed with 1.35 nearly the same risk as the pooled risk estimator for no adjustment for smoking (both statistically significant). Reulen et $a l^{8}$ found a significant risk of 1.29 for smoking-adjusted data among hairdressers and an elevated but not significant risk of 1.20 for no adjustment for smoking. This makes it likely that confounding by smoking is of minor importance even though its influence cannot be completely ruled out because quite a few studies $(\mathrm{n}=19)$ did not control for confounding.

\section{Risk by duration of job held}

To our knowledge, the association between the duration of job held as a hairdresser and the risk of bladder cancer was not tested before by meta-analysis. The risk of bladder cancer increased with the duration of job held, in particular for hairdressers with a duration of job held for $\geq 10$ years. The pooled data for the duration of job held $\geq 5$ years were also elevated, but the effect was not statistically significant. The lack of a significant effect may be due to limited study power as only three studies provided data for job held $\geq 5$ years.

Duration of working as a hairdresser was used as exposure surrogate. Because of the different ways duration was assessed in the studies, it was not possible to create mutually exclusive exposure categories, for example, the lowest category 'ever registered as hairdresser' might also contain hairdressers who worked for more than 10 years. However, our results suggest that there is an association between the duration of job held, especially for hairdressers with job held for $\geq 10$ years, and this lends additional weight to a suspected causal relationship.

\section{Time aspects and the risk of bladder cancer}

It remains an open question whether current occupational exposure to modern hair dyes and other hair products is still related to some excess bladder cancer risk among hairdressers. The data of none but one $e^{53}$ study included in our meta-analysis are not eligible to analyse this association because the studies did not specify the calendar year during which exposure occurred.

In this respect, the year of case finding is of limited value when trying to distinguish different exposure periods. Because of the long latency times (30 or 40 years) even recently conducted analyses with bladder cancer cases ascertained after $1995^{23-25}$ or after $2000^{55}$ may observe risks caused by the exposure to aromatic amines included in hair products before 1980 .

The analysis stratified for study period showed significant elevated risks, but no trend with time while Reulen et al ${ }^{8}$ found increasing risks with time in their meta-analysis. Risks of 1.18 , 1.27 and 1.48 were found for ascertained bladder cancer cases in hairdressers before 1980, between 1980 and 1989, and after 1989, respectively.

In order to determine whether occupational exposure to modern hair products is still related to a risk for bladder cancer, it would be useful to determine whether hairdressers working before 1980 and hairdressers working after 1980 have the same risk. A Swedish retrospective cohort study conducted by Czene et $a l^{53}$ is the only study that distinguishes different exposure periods. Registry data with data of four exposure periods yielded declining SMRs: the risk for males registered as hairdressers between 1960 and 1969 was 2.56 (significant). The risk decreased to 1.35 for the period $1970-1979$, to 1.25 for the period 1980-1989 and to 0.92 for the period 1990-1998 (all not significant). No increased risk estimate was found for female hairdressers, so the data were not presented. ${ }^{53}$ It remains unsettled to which extent this decline is explained by different latency periods or by a real decline in risk.

\section{CONCLUSION}

All our results taken into account, we conclude that there is good evidence for an increased risk of bladder cancer among hairdressers, in particular for hairdressers in jobs held $\geq 10$ years.

We included 42 studies in our meta-analysis: no indication of publication bias or heterogeneity was found. We found SRRs in the range from 1.25 to 1.70 which were positively associated with duration of employment, rendering a causal association between bladder cancer and job held as a hairdresser likely. The 
risks for smoking-adjusted data were more or less the same than for data with no adjustment. Potential for residual confounding cannot be ruled out but this risk seems small. It remains an open question whether hairdressers working after 1980 only, when aromatic amines with known mutagenic or carcinogenic effects were banned from hair dye ingredients in the European Union, still present an increased risk for bladder cancer.

\section{Acknowledgements We wish to thank Dana Wendeler for her great support with the management of the literature.}

Contributors All authors contributed equally to this work: AS has made substantial contributions to conception of the study, extraction of the data and interpretation of data. She has been involved in drafting the manuscript critically for important intellectual content. She has given final approval of the version to be published. GS has made substantial contributions to the extraction of data. She has been involved in revising the manuscript critically for important intellectual content. She has given final approval of the version to be published. MD has made substantial contributions to conception of the study. She has been involved in revising the manuscript critically for important intellectual content. She has given final approval of the version to be published. AN has made substantial contributions to conception and design, as well as to analysis and interpretation of data. He has been involved in drafting the manuscript. He has given final approval of the version to be published. MH has made substantial contributions to conception and design, extraction of data, as well as to analysis and interpretation of data. She has been involved in drafting the manuscript. She has given final approval of the version to be published.

Competing interests None.

Provenance and peer review Not commissioned; externally peer reviewed.

\section{REFERENCES}

1. Ames BN, Kammen HO, Yamasaki E. Hair dyes are mutagenic: identification of a variety of mutagenic ingredients. Proc Natl Acad Sci U S A 1975;72:2423-7.

2. Bolt HM, Golka K. The debate on carcinogenicity of permanent hair dyes: new insights. Crit Rev Toxicol 2007;37:521-36.

3. Golka K, Schops W, Kierfeld G, et al. [Urothelial diseases as an occupational disease] Versicherungsmedizin 1994:46:158-61.

4. Weistenhofer W, Blaszkewicz M, Bolt HM, et al. N-acetyltransferase-2 and medical history in bladder cancer cases with a suspected occupational disease (BK 1301) in Germany. J Toxicol Environ Health A 2008;71:906-10.

5. Bolt HM, Golka K. Occupational cancer-burdens of the past or actual threat? Dtsch Med Wochenschr 2007:132:133-4.

6. Turesky RJ, Freeman JP, Holland RD, et al. Identification of aminobiphenyl derivatives in commercial hair dyes. Chem Res Toxicol 2003;16:1162-73

7. La Vecchia C, Tavani A. Epidemiological evidence on hair dyes and the risk of cancer in humans. Eur J Cancer Prev 1995;4:31-43.

8. Reulen RC, Kellen E, Buntinx F, et al. A meta-analysis on the association between bladder cancer and occupation. Scand J Urol Nephrol Supp/ 2008;(218):64-78.

9. Vandenbroucke JP, von Elm E, Altman DG, et al. Strengthening the reporting of observational studies in epidemiology (STROBE): explanation and elaboration. PLoS Med 2007;4:e297.doi: 10.13771/journal.pmed.0040297.

10. Slim K, Nini E, Forestier D, et al. Methodological index for non-randomized studies (minors) development and validation of a new instrument. ANZ J Surg 2003:73:712-16.

11. Higgens JPT, Green S, eds. Cochrane handbook for systematic reviews of interventions 4.2.6. In: The Cochrane Library. Issue 4. Chichester, UK: John Wiley \& Sons, 2006:79-165.

12. West S, King V, Carey TS, et al. Systems to rate the strength of scientific evidence. Evid Rep Technol Assess (Summ) 2002;47:1-11.

13. Downs SH, Black N. The feasibility of creating a checklist for the assessment of the methodological quality both of randomised and non-randomised studies of health care interventions. J Epidemiol Community Health 1998;52:377-84.

14. Dersimonian R, Kacker R. Random-effects model for meta-analysis of clinical trials: an update. Contemp Clin Trials 2007;28:105-14.

15. Schoenberg JB, Stemhagen A, Mogielnicki AP, et al. Case-control study of bladder cancer in New Jersey. I. Occupational exposures in white males. J Natl Cancer Inst 1984;72:973-81.

16. Schumacher MC, Slattery ML, West DW. Occupation and bladder cancer in Utah. Am J Ind Med 1989;16:89-102.

17. Silverman DT, Levin LI, Hoover RN, et al. Occupational risks of bladder cancer in the United States: I. White men. J Natl Cancer Inst 1989:81:1472-80.

18. Silverman DT, Levin $\mathrm{LI}$, Hoover RN. Occupational risks of bladder cancer among white women in the United States. Am J Epidemiol 1990;132:453-61.

19. Siemiatycki J, Dewar R, Nadon L, et al. Occupational risk factors for bladder cancer: results from a case-control study in Montreal, Quebec, Canada. Am J Epidemiol 1994;140:1061-80.

20. Teschke K, Morgan MS, Checkoway $\mathrm{H}$, et al. Surveillance of nasal and bladder cancer to locate sources of exposure to occupational carcinogens. Occup Environ Med 1997; 54:443-51.

21. Gago-Dominguez M, Castelao JE, Yuan JM, et al. Use of permanent hair dyes and bladder-cancer risk. Int J Cancer 2001;91:575-9.
22. Zheng T, Cantor KP, Zhang Y, et al. Occupation and bladder cancer: a populationbased, case-control study in lowa. J Occup Environ Med 2002;44:685-91.

23. Colt JS, Baris D, Stewart $P$, et al. Occupation and bladder cancer risk in a populationbased case-control study in New Hampshire. Cancer Causes Control 2004:15:759-69.

24. Gaertner RR, Trpeski L, Johnson KC. A case-control study of occupational risk factors for bladder cancer in Canada. Cancer Causes Control 2004:15:1007-19.

25. Samanic CM, Kogevinas M, Silverman DT, et al. Occupation and bladder cancer in a hospital-based case-control study in Spain. Occup Environ Med 2008:65:347-53.

26. Cole $\mathbf{P}$, Hoover R, Friedell GH. Occupation and cancer of the lower urinary tract. Cancer 1972;29:1250-60.

27. Viadana $\mathbf{E}$, Bross ID, Houten L. Cancer experience of men exposed to inhalation of chemicals or to combustion products. J Occup Med 1976;18:787-92.

28. Howe GR, Burch JD, Miller AB, et al. Tobacco use, occupation, coffee, various nutrients, and bladder cancer. J Natl Cancer Inst 1980:64:701-13.

29. Alderson M. Cancer mortality in male hairdressers. J Epidemiol Community Health 1980;34:182-5.

30. Cartwright R. Occupational bladder cancer and cigarette smoking in West Yorkshire Scand J Work Environ Health 1982;8(Suppl 1):79-82.

31. Teta MJ, Walrath J, Meigs JW, et al. Cancer incidence among cosmetologists. J Nat/ Cancer Inst 1984:72:1051-7.

32. Dubrow R, Wegman DH. Cancer and occupation in Massachusetts: a death certificate study. Am J Ind Med 1984;6:207-30.

33. Guberan E, Raymond L, Sweetnam PM. Increased risk for male bladder cancer among a cohort of male and female hairdressers from Geneva. Int J Epidemiol 1985;14:549-54.

34. Morrison AS. Advances in the etiology of urothelial cancer. Urol Clin North Am 1984:11:557-66

35. Vineis $\mathbf{P}$, Magnani C. Occupation and bladder cancer in males: a case-control study. Int J Cancer 1985;35:599-606.

36. Pearce NE, Howard JK. Occupation, social class and male cancer mortality in New Zealand, 1974-78. Int J Epidemiol 1986;15:456-62.

37. Risch HA, Burch JD, Miller AB, et al. Occupational factors and the incidence of cancer of the bladder in Canada. Br J Ind Med 1988;45:361-7.

38. Lynge $\mathbf{E}$, Thygesen $L$. Use of surveillance systems for occupational cancer: data from the Danish National system. Int J Epidemiol 1988;17:493-500.

39. Steineck G, Plato N, Gerhardsson M, et al. Increased risk of urothelial cancer in Stockholm during 1985-87 after exposure to benzene and exhausts. Int J Cancer 1990:45:1012-17.

40. Skov T, Andersen A, Malker $\mathrm{H}$, et al. Risk for cancer of the urinary bladder among hairdressers in the Nordic countries. Am J Ind Med 1990;17:217-23.

41. Burns PB, Swanson GM. Risk of urinary bladder cancer among blacks and whites: the role of cigarette use and occupation. Cancer Causes Control 1991;2:371-9.

42. Kunze E, Chang-Claude J, Frentzel-Beyme R. Life style and occupational risk factors for bladder cancer in Germany. A case-control study. Cancer 1992:69:1776-90.

43. Pukkala E, Nokso-Koivisto P, Roponen P. Changing cancer risk pattern among Finnish hairdressers. Int Arch Occup Environ Health 1992;64:39-42.

44. Trögner A. Untersuchungen zur Epidemiologie des Harnblasenkarzinoms-Ergebnisse einer Falk-Kontrollstudie im Ruhrgebiet. Dissertation zur Erlangung des Grades eines Doktors der Medizin. Düsseldorf, Aus dem Medizinischen Institut für Umwelthygiene an der Heinrich-Heine-Universität Düsseldorf, 1991

45. Bolm-Audorff U, Jöckel KH, Kilguss B, et al. Bösartige Tumoren der ableitenden Harnwege und Risiken am Arbeitsplatz. In: Bundesanstalt für Arbeitsschutz und Arbeitsmedizin. ed. Dortmund: Wirtschaftsverlag NW, 1993.

46. Cordier S, Clavel J, Limasset JC, et al. Occupational risks of bladder cancer in France: a multicentre case-control study. Int J Epidemiol 1993:22:403-11.

47. Burnett CA, Silverman DT, Lalich NR. A comparison of analyses of occupational bladder cancer: death certificate vs. population-based case-control interview data. Am J Ind Med 1994;25:677-88.

48. Golka K, Bandel T, Urfer W, et al. Berufliche Risikofaktoren für Tumoren der Harnblase und der Prostata. In: Bundesanstalt für Arbeitsschutz. ed. Bremerhaven: Wirtschaftsverlag NW, Verlag für neue Wissenschaft, 1994: 87

49. Skov T, Lynge E. Cancer risk and exposures to carcinogens in hairdressers. Skin Pharmacol 1994:7:94-100.

50. Sorahan T, Hamilton L, Wallace DM, et al. Occupational urothelial tumours: a regiona case-control study. Br J Urol 1998;82:25-32.

51. Lamba $\mathbf{A B}$, Ward MH, Weeks JL, et al. Cancer mortality patterns among hairdressers and barbers in 24 US states, 1984 to 1995. J Occup Environ Med 2001;43:250-8.

52. Bouchardy C, Schuler G, Minder C, et al. Cancer risk by occupation and socioeconomic group among men-a study by the Association of Swiss Cancer Registries. Scand J Work Environ Health 2002;28(Suppl 1):1-88

53. Czene K, Tiikkaja S, Hemminki K. Cancer risks in hairdressers: assessment of carcinogenicity of hair dyes and gels. Int J Cancer 2003;105:108-12.

54. Ji J, Granstrom C, Hemminki K. Occupation and bladder cancer: a cohort study in Sweden. Br J Cancer 2005:92:1276-8.

55. Dryson E, T'Mannetje A, Walls C, et al. Case-control study of high risk occupations for bladder cancer in New Zealand. Int J Cancer 2008;122:1340-6.

56. Golka K, Heitmann P, Gieseler F, et al. Elevated bladder cancer risk due to colorants-a statewide case-control study in North Rhine-Westphalia. Germany J Toxicol Environ Health A 2008:71:851-5.

57. Egger M, Davey Smith G, Schneider M, et al. Bias in meta-analysis detected by a simple, graphical test. BMJ 1997;315:629-34. 